\title{
Economics of higher education in Russia
}

\author{
Larisa Bondarovskaya* \\ Industrial University of Tyumen, Department of applied mathematics and natural Sciences, 46 \\ Severnay st. Noyabrsk, Russia
}

\begin{abstract}
The paper discusses the economic aspect of modern Russian higher education. Education is one of the economic branches. The paper proposes several models of domestic economic policy in the field and some ideas for involving foreign students. The main idea of the paper is that universities have to stop hopping for government resources and act like an economic actor.
\end{abstract}

\section{Introduction}

At the moment, the sphere of higher education is undergoing serious transformations. All of them are related to environmental challenges in one way or another. The main challenges of our time include [1]:

- significant change in the labor structure, which creates a demand for new professions, which means competencies and knowledge;

- frequent changes in demand for various professions, which increases the need and importance of professional retraining;

- changes in forms of work, including switching to remote work and training;

- mass market that forces specialists to adapt to its requirements;

- lack of production in many areas, development of the IT sector in Russia and production in China;

- replacement of many professions and modern technologies;

- sharp decline not only in quality, but also in the perception of quality among modern consumers in all areas;

- high impact of state standards and regulations that do not have time to adapt to new market requirements.

As a result, a higher education institution finds itself in a situation where it needs to be a market structure or partially a market structure, and maintain a high level of competitiveness that consists of contradictory aspects.

\footnotetext{
* Corresponding author: bondarovskaya.1.v@bk.ru
} 


\section{Methods}

The article proposes several models for domestic and foreign development of educational services in Russia. The paper combines different ideas, facts, and even laws to propose and prove the realism of the models. The main methods are analysis, structuring, and estimation.

\section{Results}

\subsection{Funding models for educational institutions}

At the moment, universities are funded from several sources, and most often from a combination of them [2]:

- state or local budget;

- student tuition fees;

- sale of additional educational services (courses, advanced training, professional retraining);

- selling additional non-educational services or renting out premises for them, including canteens, copy centers, book stores, Parking, and others;

- publishing and implementing your own books and textbooks;

- grant financing.

Thus, it is clear that educational services are not limited to learning as such. The University is a complex structure that includes various types of activities. Note that some of them are closely related exclusively to physical presence and do not make sense for remote training. In other words, universities that operate as organizations and incur expenses related to the operation of buildings, structures, and territories cannot refuse them and go online for a number of reasons [3]. First, it is state property, and the University is not a simple tenant. Second, many labs can't be moved online. Third, the University bears both operating costs and receives revenue from its space. In fact, such a transition should imply a significant change in the structure of the University itself. Moreover, both organizational and physical.

\subsubsection{Competition}

It is necessary to understand that educational institutions compete with each other even if students with independent tuition fees do not come to the specialty at all.

The bottom line is that an educational institution must fill all budget places allocated by the state. To do this, its specialties and the university itself must be in demand. Students should want to spend their time and effort studying at a University.

Universities also compete with each other on average passing scores for the sum of use points. The bottom line is that applicants are divided globally into two categories [4]:

- seeking to obtain a quality education;

- aspiring to obtain an easy higher education, for the sake of having a diploma in the future.

Accordingly, the first category of students judges the University by various ratings, reviews, articles in the media, and passing scores. They want to study with other high-level students. While the second group is looking for universities where they can be taken with their low scores [5].

University cannot attract both groups of students. At the same time, taking into account state requirements, norms and standards in the field of graduated students as a percentage of the number of applicants, universities should clearly separate these two groups of students. That is why they compete with each other both in the field of educational programs and the 
quality of attracted students. Moreover, each University should act as an organization that attracts its target audience through the appropriate sales funnel.

An important aspect is that the final choice of an applicant in this field is associated with high transaction costs, which leads to more complex requirements and criteria. At the same time, competition is intensifying due to the development of distance learning and MOOCS. As a result, it becomes possible to obtain distance higher education, as well as individual courses, the result of which is possible employment. Given that the cost of such distance education is comparable to Russian, and the cost of courses is significantly lower, and employment opportunities are higher, they are significant competitors of Russian universities.

\subsubsection{University sales funnel}

So, the University is an organization that competes in the market for attracting students. Note that state universities in any case have several budget places that they must fill first. Otherwise, the program will be closed in the next few years. In the private sector, the situation is generally similar. That is why universities should choose which group of students they want to attract, while ensuring high engagement [6].

Speaking in modern economic and product terms, going to University is the first sale. While continuing training is a regular subscription renewal with high exit costs for the client. At the same time, the state University has huge costs for students due to the requirements and standards. For private universities, the situation is a little easier, since it only leads to a local decrease in income and profit, and in the absence of mass phenomena, it does not affect the overall efficiency of activities.

Either way, both public and private universities tend to retain the majority of their students until graduation. As a result, they need to attract exactly the students who fit their profile.

The standard diagram of the University's sales funnel is shown in Fig. 1.

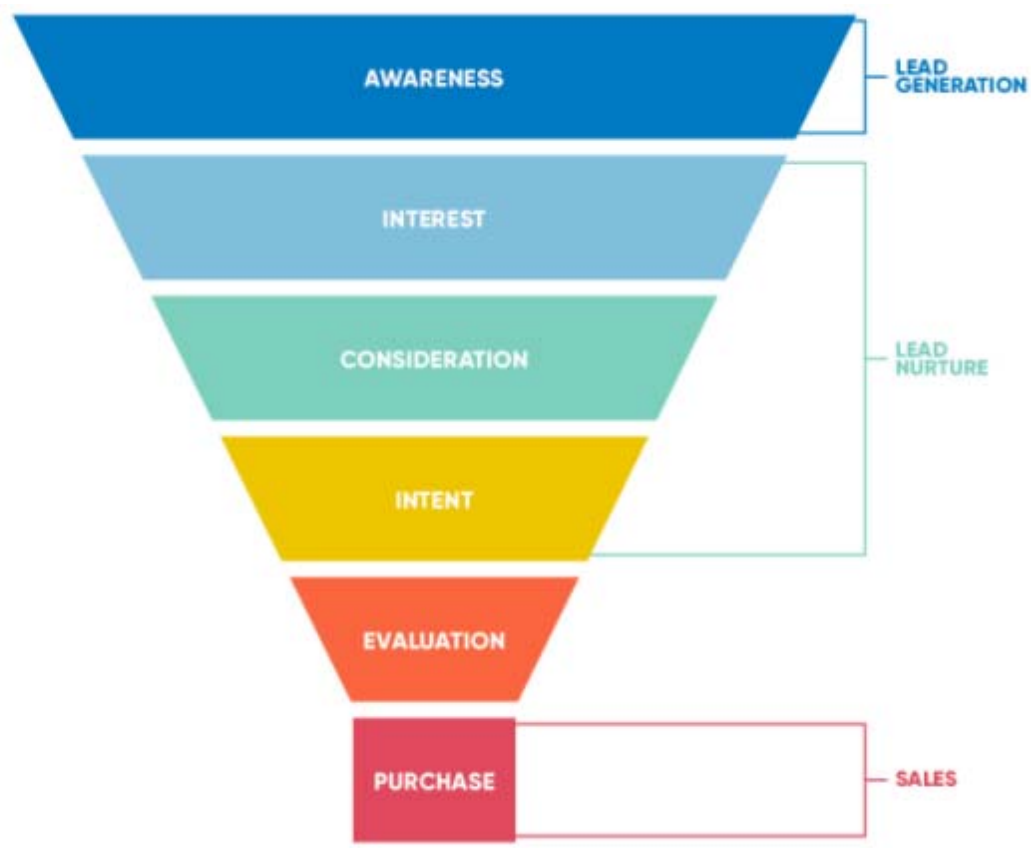

Fig. 1. University sales funnel 
It includes informing prospective students and their parents is perhaps the most wellknown and a public stage. It includes both open and hidden ads. In open form, this is contextual advertising, advertising in social networks and media, as well as advertising in additional networks, where the user is shown an ad with a link to the University, if they have recently searched for it. Hidden advertising includes sponsorship of events, various articles in the media, inclusion in ratings and reviews, and much more. Then, at the second stage, a long process of attraction is implemented, which includes [7]:

- creating interest in the University - well-known excursions and open days;

- providing information for reasoning and reflection - statistics of graduates, comparing themselves with their closest competitors;

- creating a plan to enroll - providing information about the conditions of admission, as well as the bonuses that it will give, including use points, class schedules, availability of dormitories, internships in various companies, and much more.

After that, the future student and his parents evaluate the universities and choose the most preferred ones, where they will apply in the future. At the last stage, there is a search for correspondence between the University and its applicants.

The sales funnel must necessarily take into account the international competition of universities, which has increased due to the development of distance education. In fact, each University must justify to the applicant why it is better than its foreign counterparts. Or focus only on those students who can't pull the level of stronger competitors.

\subsubsection{Key mistakes}

Universities most often make several key mistakes [8]:

- they make extensive mass, non-specific advertising, attracting a lot of students and not offering them a sufficient variety of training programs;

- they advertise too narrowly and do not attract enough applicants;

- they misjudge their target audience and attract applicants who do not meet the University level;

- their engagement activities are too boring and one-sided;

- University has few opportunities for internships and partner programs with employers.

\subsection{Future transformations}

Future transformations of higher education in Russia and its economy will largely be determined by both changes in legislation and external challenges. At the moment, many teachers in state and non-state universities are frankly not qualified enough. At the same time, the University management has a small number of ways to actually assess their knowledge and competencies.

It is at this point that the availability of free or very cheap specialized courses on the Internet becomes the strongest competitor of universities. Why? It's about low institutional barriers to entry and exit. Such courses and educational programs can be used by a huge number of people, including both students who do not have a diploma, and University graduates who do not have the right to receive higher education for free.

At the same time, it is much easier to enroll in courses or drop out of them than to go to University. To remain competitive, universities need to develop both core and auxiliary training programs, as well as attract strong companies for internships. In fact, they should develop everything that can be attributed to a competitive advantage.

Increased environmental challenges have created the need for universities to develop new forms and formats of education. That is why not only the format of training will change in 
the coming years. It is logical to assume a significant transformation of educational programs and approaches to training.

\section{Discussion and Conclusion}

When considering various options for economic incentives to increase the effectiveness of training, it is necessary to understand that fundamental changes in the financing system are more influenced by socio-political and macroeconomic factors than by factors that actually improve the quality of training [3].

The preservation of guarantees of free professional education is, in fact, an anachronism of the former social structure of our society [5]. Today, it is more suitable for the current mechanism of public administration than for increasing the effectiveness of education.

The launch of economic levers to influence the increase in the quality of labor training will reduce the participation of the budget mechanism in the redistribution of financial resources. Under any circumstances, this bureaucratic distribution will always be less effective than the simplest market methods [8]. An example is the current functioning of federal education management bodies, when the ability to perform such an absolutely formal procedure as timely transfer of funds from the budget to institutions is reduced against the background of the emasculation of the content component of training.

\section{References}

1. N. Gamlo, English Language Teaching, 12(4), 49 (2019)

2. J. Schlax, et al., Studies in Educational Evaluation 66, 100900 (2020)

3. R.K. Toutkoushian, M.B. Paulsen, New York, NY: Springer 10, 978 (2016)

4. K. Denny, D. Flannery, Palgrave Macmillan, Cham, 27 (2017)

5. C. Holmes, K. Mayhew, Oxford review of economic policy, 32.4, 475 (2016)

6. R.A. Madani, Higher Education Studies, 9, 100 (2019)

7. R. A. Cohen, et al., Journal of Kidney Diseases, 68, 203 (2016)

8. F. Gajardo, N. Grau, International Journal of Educational Development, 65, 123 (2019) 